\title{
Reconfigurable low-emissivity optical coating using ultra-thin phase change materials
}

Nathan Youngblood*,1,3, Clément Talagrand ${ }^{2}$, Benjamin F. Porter ${ }^{1}$, Carmelo Guido Galante $^{4}$, Steven Kneepkens ${ }^{4}$, Graham Triggs ${ }^{2}$, Syed Ghazi Sarwat ${ }^{1}$, Dmitry Yarmolich ${ }^{5}$, Ruy S. Bonilla ${ }^{1}$, Peiman Hosseini ${ }^{2}$, Robert A. Taylor ${ }^{6}$, and Harish Bhaskaran ${ }^{*, 1}$

${ }^{1}$ Department of Materials, University of Oxford, Oxford, OX1 3PH, UK

${ }^{2}$ Bodle Technologies Ltd., Begbroke, OX5 1PF, UK

${ }^{3}$ Department of Electrical and Computer Engineering, University of Pittsburgh, Pittsburgh, PA 15261, USA

${ }^{4}$ Eckersley O'Callaghan Ltd, London, WC1X 8HB, UK

${ }^{5}$ Plasma App Ltd., Didcot, OX11 0QX, UK

${ }^{6}$ Department of Physics, University of Oxford, Oxford, OX1 3PJ, UK

*E-mail: nathan.youngblood@pitt.edu and harish.bhaskaran@materials.ox.ac.uk 


\section{Supplementary Note 1}

\section{Refractive Index and Crystallization Temperature of PCM}

In order to design our optical stack for the smart glazing, we first measured the refractive indices of the $\mathrm{ZnS}: \mathrm{SiO}_{2}, \mathrm{Ag}$, and $\mathrm{Ge}_{20} \mathrm{Te}_{80}$ (Sn-doped and undoped) using ellipsometry. Samples were prepared with roughly $50 \mathrm{~nm}$ of sputtered material on silicon substrates. For the $\mathrm{Ge}_{20} \mathrm{Te}_{80}$ samples, ellipsometric data was taken before and after crystallization on a hotplate. Fig. S1a-b plots the real and imaginary components of the undoped and doped $\mathrm{Ge}_{20} \mathrm{Te}_{80}$ in both the as-deposited amorphous and as-annealed crystalline states. The imaginary component of the refractive index increases from low absorption in the amorphous state to appreciable absorption in the crystalline state for near-infrared wavelengths. This change in $k$ causes the modulation we observe near-infrared as seen in Fig. $2 \mathbf{e}$ and $\mathbf{2 f}$ of the main text. We also measured the crystallization temperature $\left(\mathrm{T}_{\mathrm{x}}\right)$ of our doped-Ge ${ }_{20} \mathrm{Te}_{80} \mathrm{PCM}$ used in Fig. 4 of the main text (Fig. S1c) which shows a transition temperature of $121^{\circ} \mathrm{C}$.
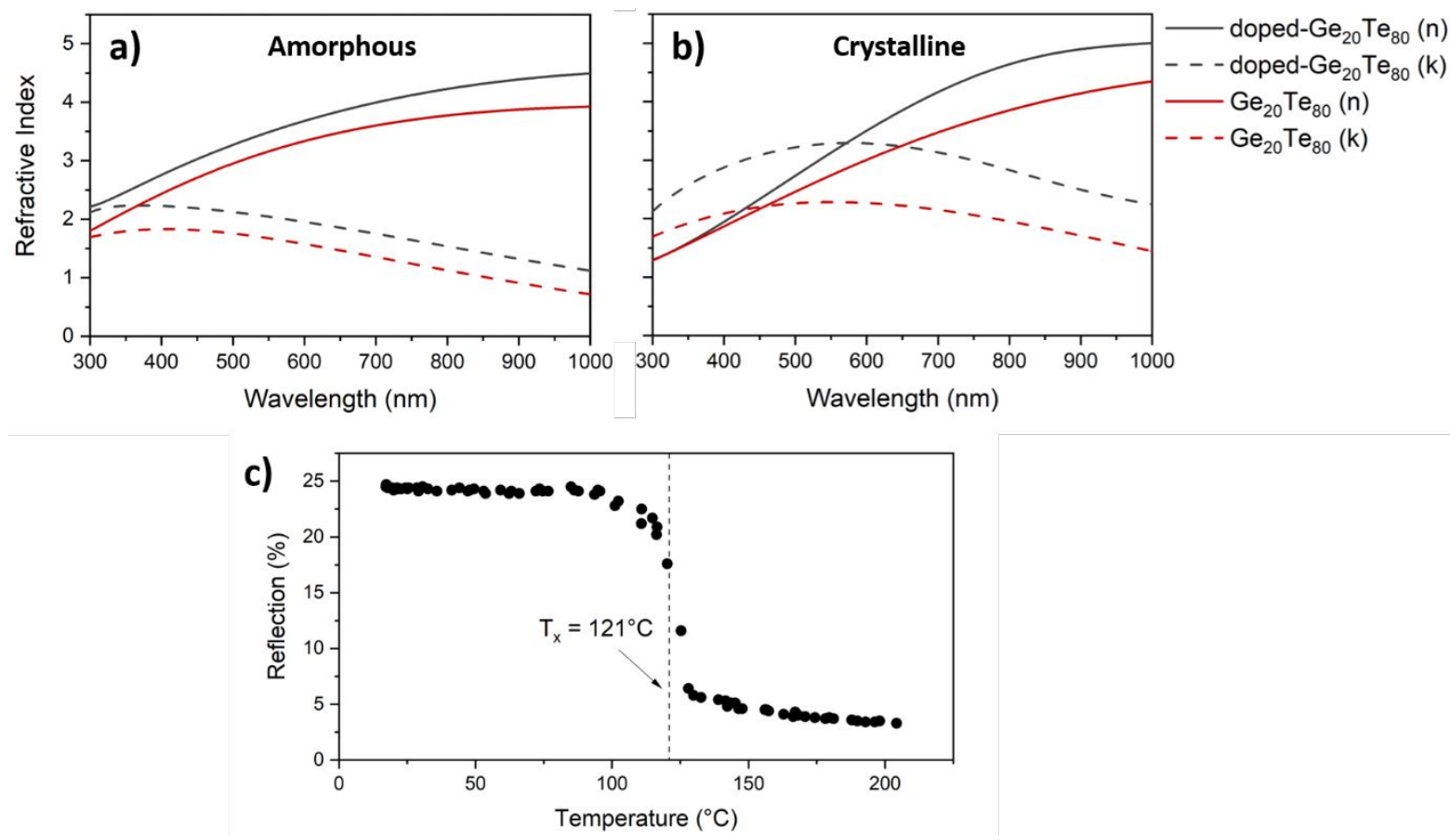

Fig. S1: a) and b) Refractive index of doped and undoped $\mathrm{Ge}_{20} \mathrm{Te}_{80}$ as measured by ellipsometry. A significant change is observed in both the real and imaginary component of the refractive index. Notably, the absorption over the near-infrared wavelengths increases when the material is in the crystalline state. c) Crystallization temperature of Sn-doped $\mathrm{Ge}_{20} \mathrm{Te}_{80}$ as determined by measuring the optical reflection as a function of temperature. 


\section{Supplementary Note 2}

\section{E-field Distribution in Optical Stack}

To better understand the design of our smart glazing, we calculated the normalized electric field intensity as a function of wavelength from the visible to near-infrared (see Fig. S2) using a transfer matrix method approach ${ }^{1}$. We observe a significant increase in the field intensity located in the PCM layer for infrared wavelengths compared to visible ones. This allows a large modulation of the infrared reflection/absorption when state of the PCM is changed. The spacing of the dielectric $(\mathrm{ZnS})$ between the Ag and PCM layers allows us to adjust the wavelengths that are either transmitted or reflected. Adding more Ag and dielectric layers beneath the PCM allows for sharper transitions between the transmission/reflection edge at UV and near-infrared wavelengths at the cost of reduced transmission in the visible.
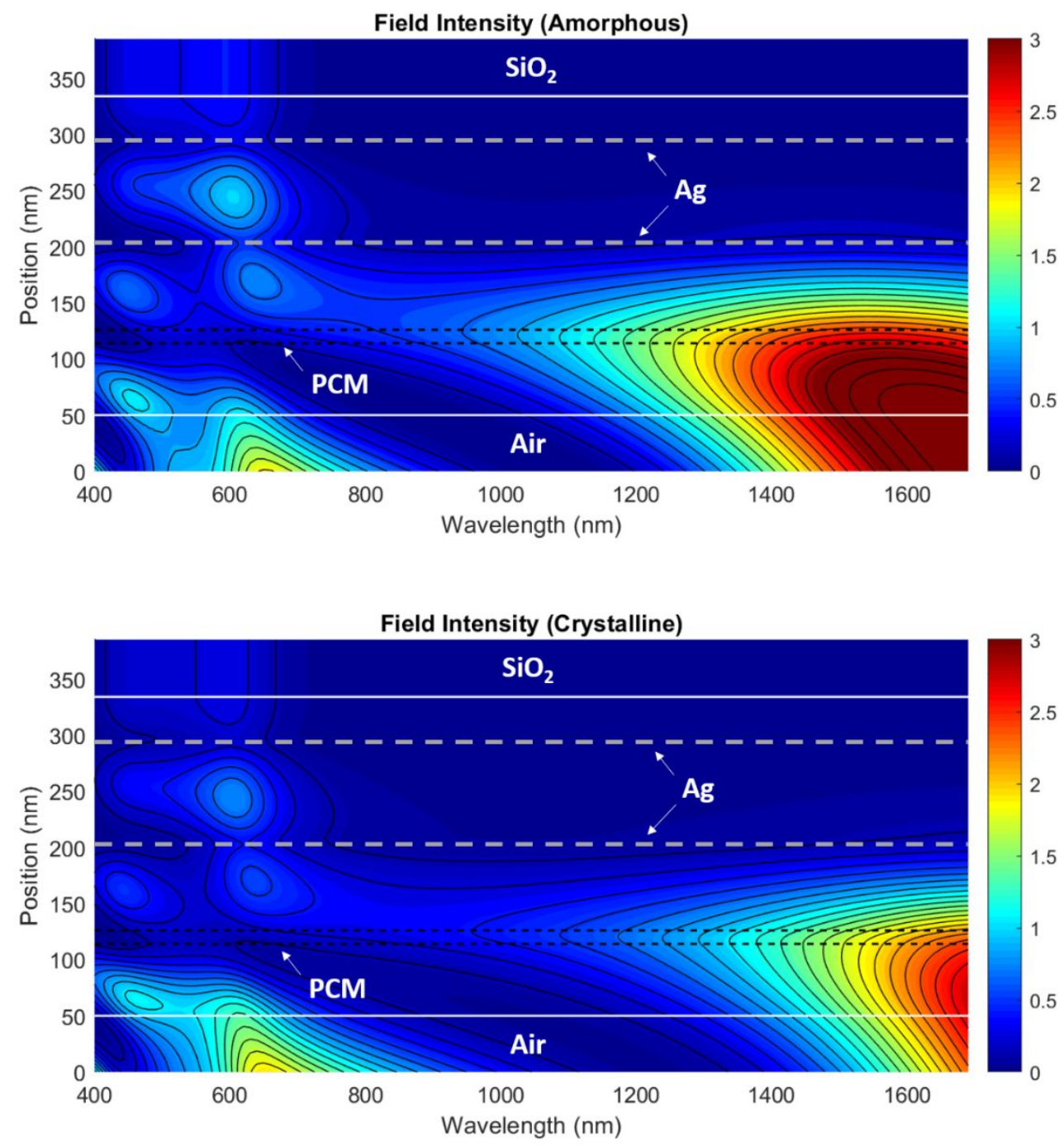

Fig. S2: Electric field intensity distribution (normalized to a uniform input field amplitude of unity) in smart glazing. The center of Ag layers is denoted by gray dashed lines and the top and bottom PCM interfaces are denoted with black dashed lines. In both states, the field intensity in the PCM layer is at a minimum for visible wavelengths while for wavelengths beyond $800 \mathrm{~nm}$, the maximum field intensity is localized in the PCM layer which provides greater modulation for near-IR wavelengths. 


\section{Supplementary Note 3}

\section{Angular Dependence}

To test the response of our smart glazing colour with the viewing angle, we simulated the angular colour dependence for both the amorphous and crystalline states. As can be seen from Fig. S3, we observer a shift in the reflected colour from blue to red as the viewing angle increases from 0 to 60 degrees in 5 degree steps. The transmitted colour, on the other hand, changes very little with viewing angle. This is important for a consistent viewing experience for the building's occupants as colouration of external objects which varies with viewing angle is undesirable.
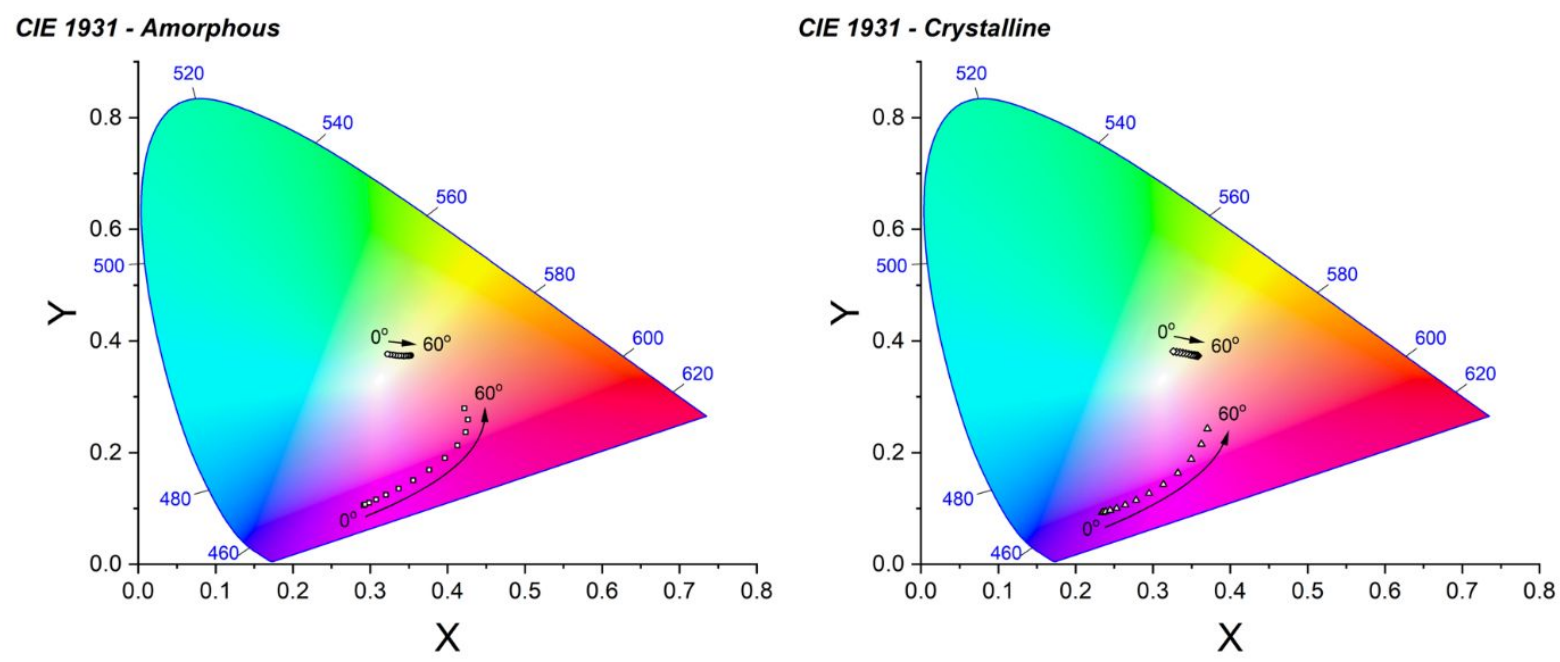

Fig. S3: Simulated angle dependent reflection (squares and triangles) and transmission (circles and diamonds) colour response of our fabricated smart glazing when the PCM is in the amorphous and crystalline state. Points are separated by 5 degree steps ranging from 0 to 60 degrees. A normalized AM1.5 solar spectrum was used as the illumination source. Very little change is observed in the angular dependence of the transmission while the colour upon reflection becomes redder as the observation angle increases from 0 to 60 degrees. 


\section{Supplementary Note 4}

\section{Manufacturability}

In order to study the manufacturability of the smart glazing, we have allowed the individual layers to randomly vary by as much as $2 \%$ in thickness (RMS error) which is an achievable thickness tolerance in the thin film industry today. A sample size of 200 randomly generated optical stacks was used to calculate the statistics in Fig. S4 and Fig. S5. As can be seen from Fig. S4, the simulated spectra are largely unaffected by small variations in the thickness of the individual layers which allows for reliable large-scale manufacturing of such smart glazings. Fig. S5 shows scatter plots of the transmitted and reflected colours of the randomly generated stacks when variations in thickness are present demonstrating that the aesthetic properties can be preserved as well during manufacturing variations.

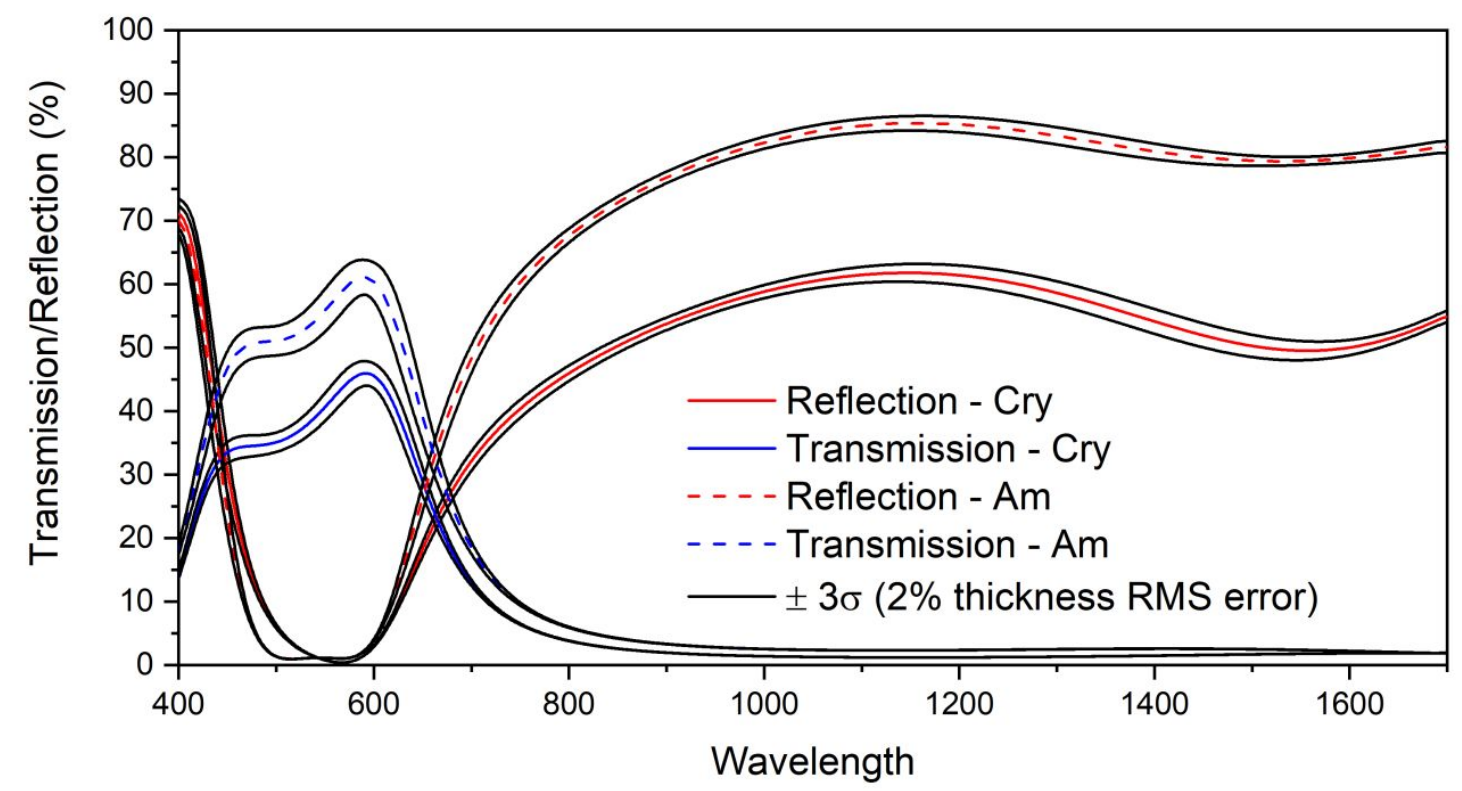

Fig. S4: Manufacturability study of smart glazing transmission and reflection spectra. Ideal spectra matched exactly to the design are shown as red and blue lines with black curves showing the maximum and minimum bounds for three standard deviations. 

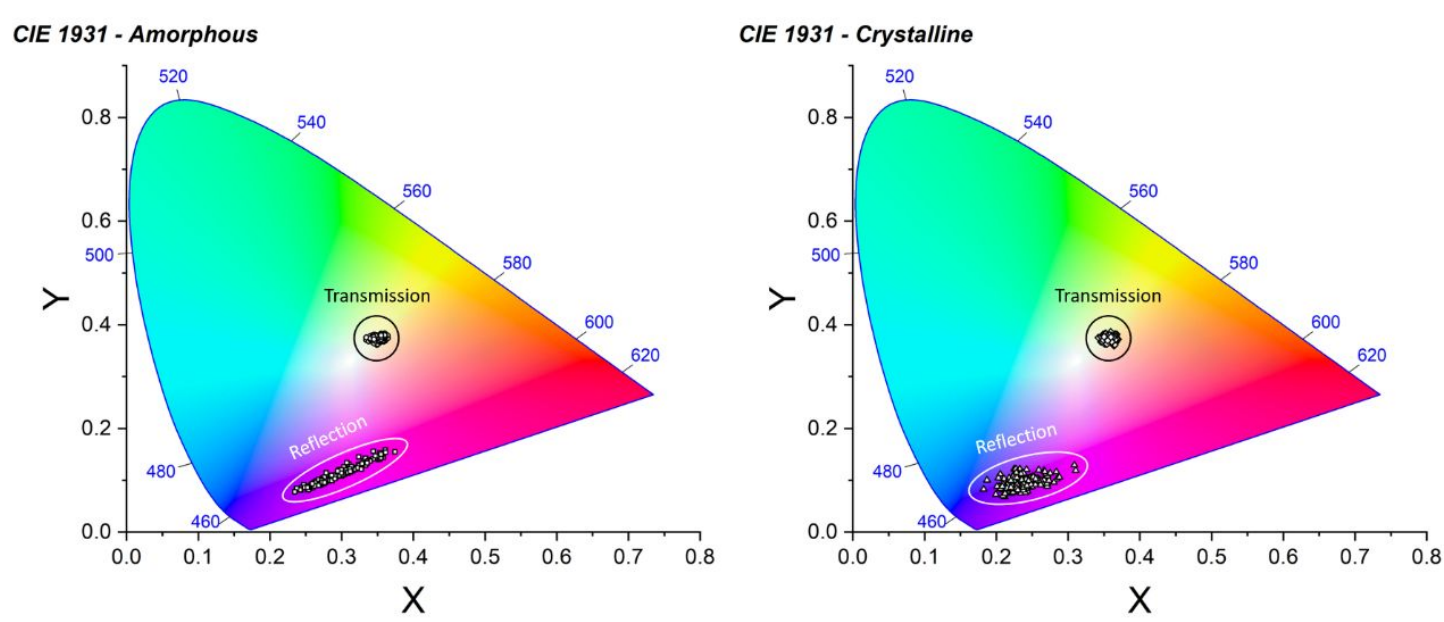

Fig. S5: Variability in the transmitted and reflected colour of the smart glazing at normal incidence for 200 randomly generated designs with errors in the thickness of the individual layers. A normalized AM1.5 solar spectrum was used as the illumination source. The reflected colour is much more strongly effected than the transmitted colour of the smart windows. 


\section{Supplementary Note 5}

\section{Single vs. Double Glazing}

In order to characterize the effects on thermal efficiency of our smart glazing in a single vs. double glazed configuration, the measured optical transmission and reflection spectra from the UV to the far-infrared were imported into Optics 6 and WINDOW 7 (architectural tools provided by Lawrence Berkeley National Laboratory's Windows and Envelope Group ${ }^{2}$ ) for heat transfer analysis. The different window configurations shown in Fig. S6 were analysed for U-value (a measure of how much heat escapes through the window), g-value (defined as the total energy transfer via direct solar transmittance and absorption/re-emission and convection), and average visible transmittances.

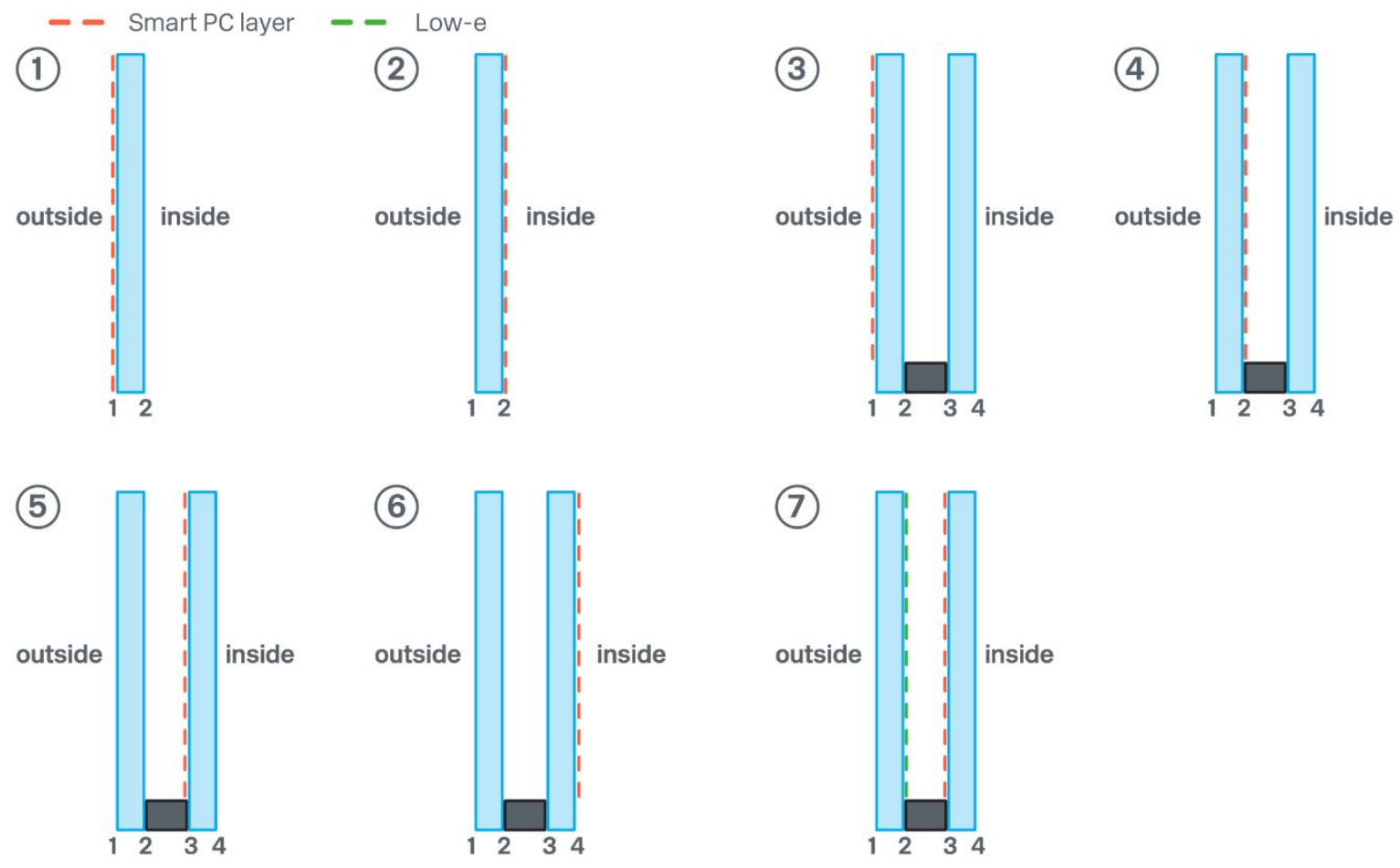

Fig. S6: Seven possible designs for the smart window with single and double glazing configurations. Design \#5 provides the highest modulation of solar energy while decreasing the overall U-value of the window.

Using this software tool, the highest performing design (\#5 in Fig. S6) is the double glazed unit with the smart PCM layer on surface \#3. This is to be expected as the double glazing serves to prevent convective loss of harvested solar energy, while the smart PCM layer preferentially absorbs near-infrared light and re-radiates thermal energy via surface \#4. The addition of a low-e coating on surface \#2 (design \#7 in Fig. S6) reduces the modulation efficiency of our window by reflecting near-infrared solar radiation and transmitting only visible light. In this case, the smart PCM layer cannot make use of the near-infrared spectrum where the modulated absorption is the highest. Table S1 summarizes the results of this study for the designs in Fig. S6. 


\section{Configuration and state $\quad$ U-value $\left(\mathrm{W} / \mathrm{m}^{2} \cdot \mathrm{K}\right) \quad$ g-value $\quad$ Light transmission (\%)}

\begin{tabular}{|l|c|c|c|}
\hline 1. Single glazing: Am & 5.7 & 0.31 & 52 \\
\hline 1. Single glazing: Cry & 5.7 & 0.35 & 41 \\
\hline 2. Single glazing: Am & 5.7 & 0.25 & 52 \\
\hline 2. Single glazing: Cry & 5.7 & 0.22 & 41 \\
\hline 3. Double glazing: Am & 2.6 & 0.26 & 48 \\
\hline 3. Double glazing: Cry & 2.6 & 0.27 & 37 \\
\hline 4. Double glazing: Am & 1.46 & 0.22 & 47 \\
\hline 4. Double glazing: Cry & 1.46 & 0.19 & 37 \\
\hline 5. Double glazing: Am & 1.46 & 0.38 & 47 \\
\hline 5. Double glazing: Cry & 1.46 & 0.46 & 37 \\
\hline 6. Double glazing: Am & 2.6 & 0.29 & 48 \\
\hline 6. Double glazing: Cry & 2.6 & 0.27 & 37 \\
\hline 7. Double glazing: Am & 1.16 & 0.31 & 40 \\
\hline 7. Double glazing: Cry & 1.16 & 0.34 & 31 \\
\hline
\end{tabular}

Table S1: Calculated performance for each glazing configuration from Supplementary Figure 6 in terms of U-value, g-value, and light transmittance. Design \#5 maximizes the change in gvalue while minimizing the U-value in both states. 


\section{Supplementary Note 6}

\section{Smart Glazing Product Comparison}

Using the optical and thermal metrics from the previous section, we compared the performance of our PCM smart window (design \#5 from Fig. S6) with currently available smart glazing technology. As not all smart glazing technologies have freely available spectral data for direct comparison, we focus on electrochromic smart-tinting glass and dynamic thermochromic glass, which are commercially available smart window technologies ${ }^{3,4}$. Additionally, we compare our smart PCM layers with a standard and a high performance low-e coating, both of which are commercially available ${ }^{5,6}$. Again, all coatings are evaluated using Optics 6 and WINDOW 7 software with the configurations shown in Fig. S7.

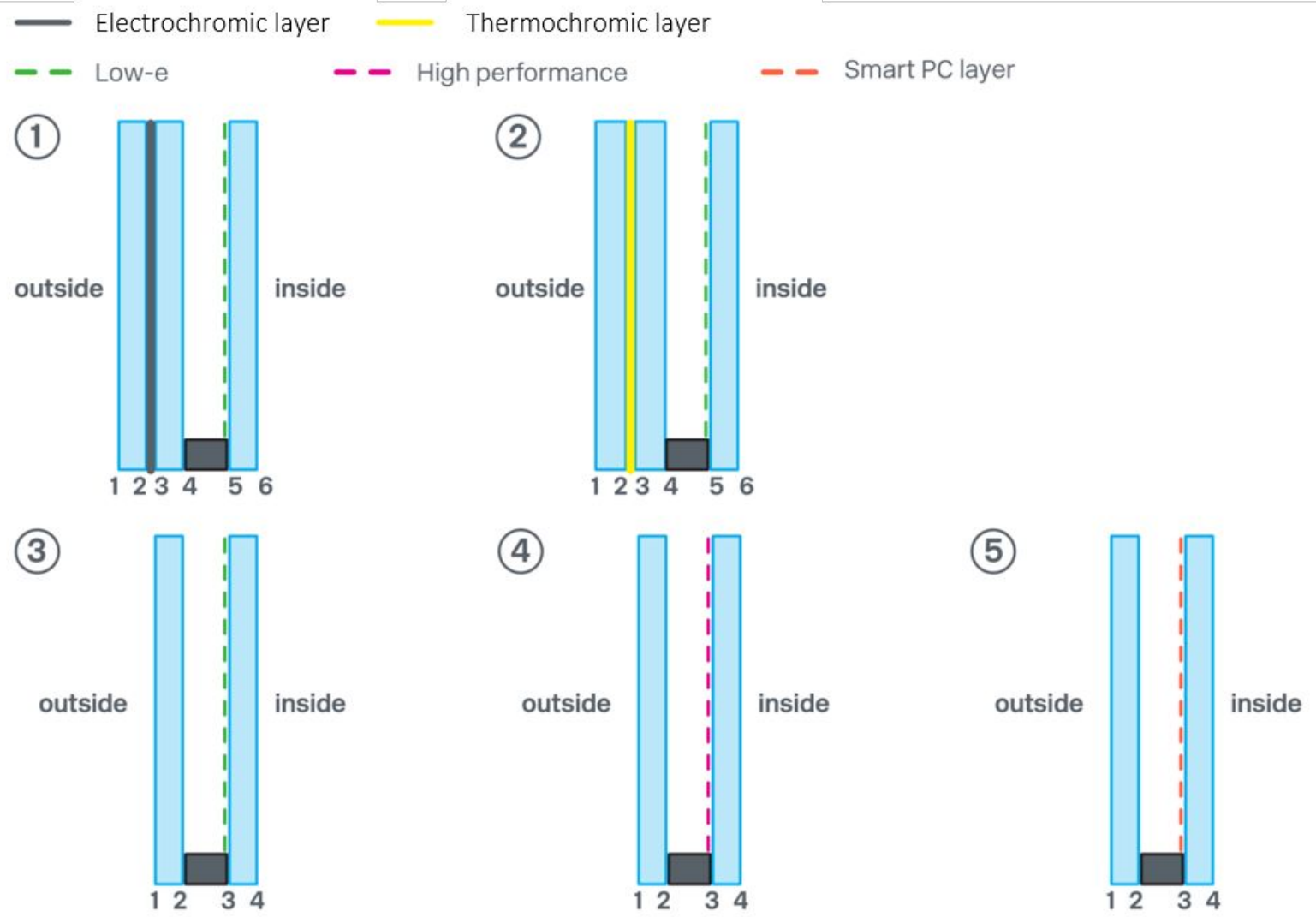

Fig. S7: Glazing configurations investigated in this comparative study.

\begin{tabular}{|l|l|l|c|c|c|c|c|}
\hline \multicolumn{2}{|c}{ Technology } & $\begin{array}{c}\text { Active/ } \\
\text { Passive }\end{array}$ & $\begin{array}{c}\text { g-value } \\
(\text { max) }\end{array}$ & $\begin{array}{c}\text { g-value } \\
\text { (min) }\end{array}$ & $\begin{array}{c}\text { LT } \\
(\mathbf{m a x})\end{array}$ & $\begin{array}{c}\text { LT } \\
(\mathbf{m i n})\end{array}$ & $\begin{array}{c}\text { U-value } \\
\left(\mathbf{W} / \mathbf{m}^{2} \cdot \mathbf{K}\right)\end{array}$ \\
\hline 1 & Electrochromic 1 & Active & $47 \%$ & $15 \%$ & $66 \%$ & $2 \%$ & 1.21 \\
\hline 2a & $\begin{array}{l}\text { Thermochromic 1 } \\
\text { moderate climate } \\
\left(15^{\circ} \mathrm{C}-45^{\circ} \mathrm{C}\right)\end{array}$ & Passive & $51 \%$ & $39 \%$ & $62 \%$ & $32 \%$ & 1.20 \\
\hline
\end{tabular}




\begin{tabular}{|l|l|c|c|c|c|c|c|}
\hline $2 \mathrm{~b}$ & $\begin{array}{l}\text { Thermochromic } 2 \\
\text { extreme climate } \\
\left(5^{\circ} \mathrm{C}-65^{\circ} \mathrm{C}\right)\end{array}$ & Passive & $52 \%$ & $30 \%$ & $64 \%$ & $9 \%$ & 1.20 \\
\hline 3 & Low-e coating & Static & $60 \%$ & $60 \%$ & $80 \%$ & $80 \%$ & 1.23 \\
\hline 4 & $\begin{array}{l}\text { High performance } \\
\text { coating }\end{array}$ & Static & $43 \%$ & $43 \%$ & $69 \%$ & $69 \%$ & 1.15 \\
\hline 5 & $\begin{array}{l}\text { PCM smart } \\
\text { window } \\
\text { (double-glazing) }\end{array}$ & Active & $47 \%$ & $38 \%$ & $47 \%$ & $37 \%$ & 1.46 \\
\hline
\end{tabular}

Table S2: Comparison of light transmittance and g-value ranges for various active, passive, and static window technologies investigated in this product comparison study. Note: Comparison windows $1,2 \mathrm{a}$, and $2 \mathrm{~b}$ include a static low-e coating in addition to the electrochromic/thermochromic active layers (see Fig. S7).

From these results, we can see that the majority of the change in g-value from electrochromic and thermochromic can be attributed to modulation of the visible region of the solar spectrum rather than the infrared. Our PCM smart glazing, on the other hand, shows a smaller change in LT (minimum LT is greater than all three of the active smart windows studied) while the majority of the change in g-value can be attributed to modulation of the near-infrared. While the change in g-value for our PCM smart glazing is lower in magnitude than the commercial smart window technologies in this study, we emphasize the fundamental difference between modulating the visible and near-infrared. Using the thermochromic and electrochromic window designs shown in Fig. S7, it is impossible to harvest a significant fraction of energy from the near-infrared spectrum due to the necessity of a low-e coating on surface $\# 5$ of designs $\# 1$ and $\# 2$. This low-e coating is necessary to meet building regulation requirements by reducing both the transmission of far-infrared radiation and the amount of re-emitted solar energy absorbed in the active layer. The second aspect is the fundamental limitation of a transmissive-absorptive smart window technology compared with our reflective-absorptive design. Based on these results, we see a clear path toward improving our initial results to achieve a competitive performance compared with commercially available smart window technologies:

1. Emissivity: In order to meet statutory building requirements in Europe, the emissivity of the PCM smart glazing needs to be reduced such that the current Uvalue of $1.46 \mathrm{~W} / \mathrm{m}^{2} \cdot \mathrm{K}$ is below $1.1 \mathrm{~W} / \mathrm{m}^{2} \cdot \mathrm{K}$. This is possible by optimizing the reflection of the optical stack for wavelengths beyond $2.5 \mu \mathrm{m}$ which was outside of the design parameters of this initial demonstration.

2. Light transmittance and g-value: By exploring different compositions of GeTe and other phase-change chalcogenides, it could be possible to find a material with lower absorption in the visible - a factor which limits our current transmission at visible wavelengths (see Supplementary Figure 1). Decreasing the extinction coefficient in the visible would allow a thicker PCM layer to be used and enable larger changes in the g-value without sacrificing light transmittance.

3. Dynamic U-value: One unique approach to improving the total energy modulation of our smart window is exploiting designs which have appreciable change in the emissivity when the PCM is switched between its amorphous and crystalline states ${ }^{16}$. 
Glass technologies with dynamic U-values do not currently exist on the market; however, the use of a dynamic U-value may help in reducing heating loads in winter (when lower U-values are required) and cooling loads in summer (when higher Uvalues are beneficial). Having a design where the emissivity is lower in the crystalline state than in the amorphous state would prevent unwanted heat loss due to radiation back into the environment during the winter months (low U-value), while increasing heat dissipation from a building in the summer months (high U-value).

\section{Comparison of Solar Modulation}

To provide a direct comparison of our PCM smart glazing with other reports in literature, we summarize the key properties of dynamic glazings in Table S3. We note that due to absorption of solar radiation during switching, most of the works listed in Table 3 require the addition of a low-e coating in a double-pane configuration (see Fig. S7 designs 1 and 2 as examples). The addition of glass panes and a low-e coating may negatively impact the reported values of $\Delta \mathrm{T}_{\text {solar }}$ and $\mathrm{T}_{\text {vis }}$ listed below.

\begin{tabular}{|c|c|c|c|c|c|c|c|}
\hline Technology & $\begin{array}{l}\text { Active/ } \\
\text { Passive }\end{array}$ & $\begin{array}{l}\text { Solar } \\
\text { Mod. }\end{array}$ & $\begin{array}{c}\mathrm{T}_{\mathrm{vis}} \\
(\mathbf{m a x})\end{array}$ & $\begin{array}{c}\mathrm{T}_{\mathrm{vis}} \\
(\mathrm{min})\end{array}$ & Emissivity & Visibility & Ref \\
\hline Low-e coating & Static & $0 \%$ & $84 \%$ & $84 \%$ & 0.1 & $\begin{array}{l}\text { Specular } \\
\text { (clear) }\end{array}$ & \\
\hline $\begin{array}{l}\text { High performance } \\
\text { low-e coating }\end{array}$ & Static & $0 \%$ & $69 \%$ & $69 \%$ & 0.03 & $\begin{array}{l}\text { Specular } \\
\text { (clear) }\end{array}$ & \\
\hline $\begin{array}{c}\mathrm{VO}_{2} / \mathrm{FTO} \\
\mathrm{ARC}+\mathrm{VO}_{2} / \mathrm{FTO}\end{array}$ & $\begin{array}{l}\text { Passive } \\
\left(90^{\circ} \mathrm{C}\right)\end{array}$ & $\begin{array}{l}4.35 \% \\
8.81 \%\end{array}$ & $\begin{array}{l}35.1 \% \\
44.0 \%\end{array}$ & $\begin{array}{l}34.0 \% \\
38.2 \%\end{array}$ & $0.13-0.24$ & $\begin{array}{l}\text { Specular } \\
\text { (yellow/ } \\
\text { brown) }\end{array}$ & 7 \\
\hline $\begin{array}{l}\mathrm{VO}_{2} \text { composite } \\
\text { foil }\end{array}$ & $\begin{array}{l}\text { Passive } \\
\left(90^{\circ} \mathrm{C}\right)\end{array}$ & $22.3 \%$ & $45.6 \%$ & $40.0 \%$ & - & $\begin{array}{l}\text { Specular } \\
\text { (yellow/ } \\
\text { brown) }\end{array}$ & 8 \\
\hline $\begin{array}{c}\mathrm{VO}_{2} \text { nanoparticle } \\
\text { array }\end{array}$ & $\begin{array}{l}\text { Passive } \\
\left(95^{\circ} \mathrm{C}\right)\end{array}$ & $13.2 \%$ & $46.1 \%$ & $45.8 \%$ & - & $\begin{array}{l}\text { Specular } \\
\text { (light } \\
\text { brown) }\end{array}$ & 9 \\
\hline $\begin{array}{c}\text { Hydrogel } \\
\text { microparticles }\end{array}$ & $\begin{array}{l}\text { Passive } \\
\left(35^{\circ} \mathrm{C}\right)\end{array}$ & $81.3 \%$ & $87.2 \%$ & $\sim 0 \%$ & - & $\begin{array}{l}\text { Opaque } \\
\text { (white) }\end{array}$ & 10 \\
\hline $\begin{array}{c}\mathrm{ITO} / \mathrm{NbO}_{\mathrm{x}} \\
\text { Nanoparticles } \\
(130 \mathrm{~s})\end{array}$ & $\begin{array}{l}\text { Active } \\
(4 \mathrm{~V}) \\
(1.5 \mathrm{~V})\end{array}$ & $\begin{array}{c}6 \% \\
31 \%\end{array}$ & $\begin{array}{l}94.3 \% \\
94.3 \%\end{array}$ & $\begin{array}{l}93.9 \% \\
54.7 \%\end{array}$ & - & $\begin{array}{l}\text { Specular } \\
\text { (clear) } \\
\text { (yellow) }\end{array}$ & 11 \\
\hline $\begin{array}{c}\text { Commercial } \mathrm{WO}_{3} \\
(8-12 \mathrm{~min})\end{array}$ & Active & $50 \%$ & $75 \%$ & $8 \%$ & - & $\begin{array}{c}\text { Specular } \\
\text { (dark blue) }\end{array}$ & 12 \\
\hline $\begin{array}{l}\text { AZO nanocrystals } \\
(60 \mathrm{~ms})\end{array}$ & Active & $20 \%$ & $85 \%$ & $82 \%$ & - & $\begin{array}{l}\text { Specular } \\
\text { (clear) }\end{array}$ & 13 \\
\hline $\begin{array}{c}\mathrm{Cu}-\mathrm{Ag} \text { electrolyte } \\
\text { (3 min) }\end{array}$ & Active & $\sim 70 \%$ & $81 \%$ & $4 \%$ & - & $\begin{array}{l}\text { Opaque } \\
\text { (black) }\end{array}$ & 14 \\
\hline $\begin{array}{c}\text { Commercial SPD } \\
(100-200 \mathrm{~ms})\end{array}$ & Active & $\sim 50 \%$ & $55 \%$ & $5 \%$ & - & $\begin{array}{l}\text { Opaque } \\
\text { (black) }\end{array}$ & 15 \\
\hline $\begin{array}{l}\text { PCM glazing } \\
(<200 \mu \mathrm{s})\end{array}$ & Active & $12.3 \%$ & $52.4 \%$ & $40.8 \%$ & $0.11-0.14$ & $\begin{array}{l}\text { Specular } \\
\text { (clear) }\end{array}$ & $\begin{array}{l}\text { this } \\
\text { work }\end{array}$ \\
\hline
\end{tabular}


Table S3: Comparison of light transmittance and solar modulation for various active, passive, and static window technologies reported in the literature. Note: Reported solar modulation for PCM glazing is $\Delta \mathrm{g}$ which includes the effects of solar transmission and absorption in addition to thermal radiation. Optical properties for low-e coatings were taken from the EnergyPlus glazing material database.

A summary of Table $\mathbf{S 3}$ can be seen in Fig. $\mathbf{S 8}$ where we plot the reported solar modulation against the minimum visible transmittance for various dynamic window technologies.

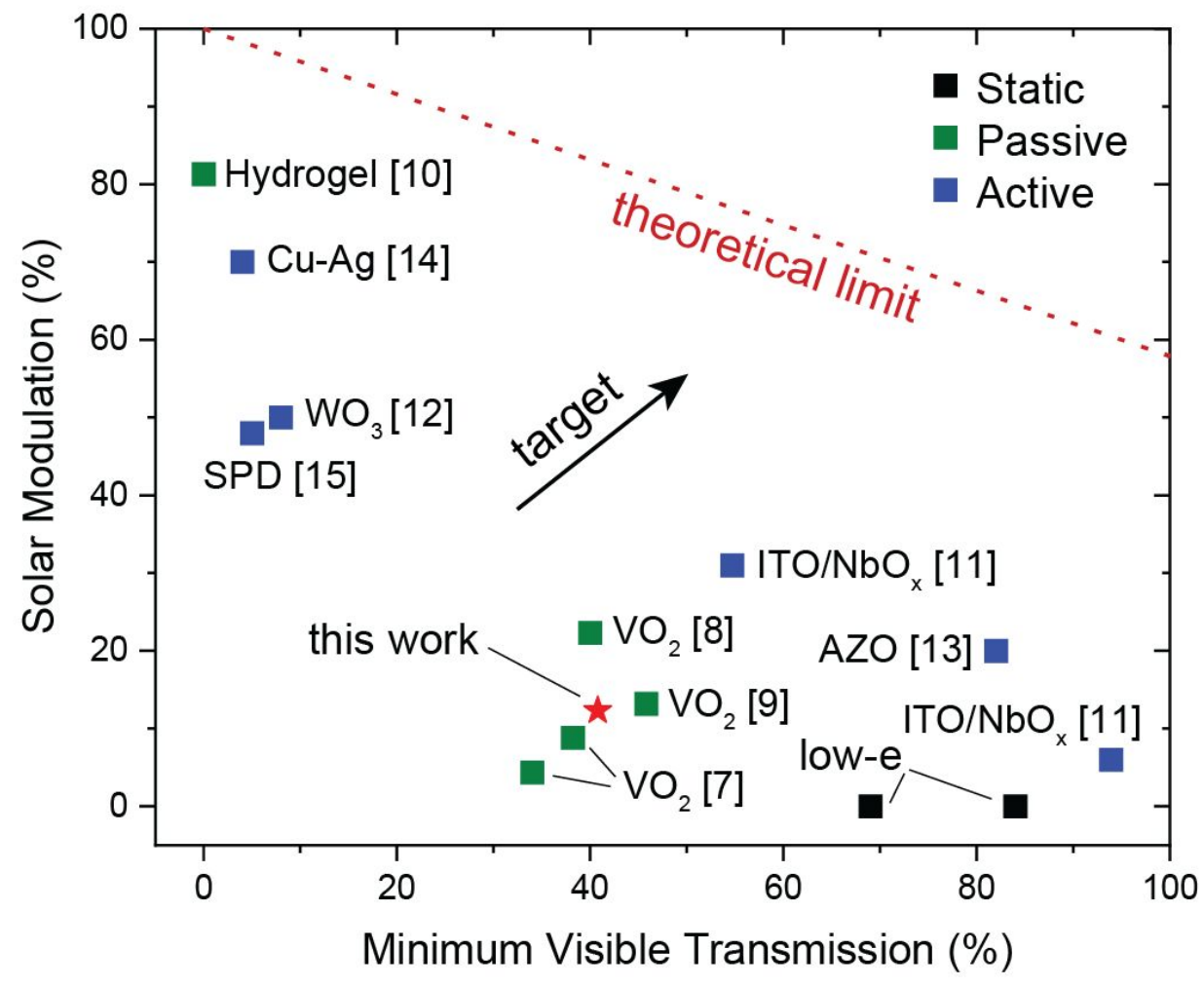

Fig. S8: Comparison of solar modulation and minimum visible transmission for various active and passive window technologies from Supplementary Table 3. It is important to note that the minimum and maximum g-value of a window is more directly related to a building's heating and cooling load. 


\section{Supplementary Note 7}

\section{Energy Savings Comparison}

To compare the benefits of our approach with available static window designs, we used EnergyPlus 9.4.0 (https://energyplus.net/) to simulate the energy savings of our smart window installed in an office building compared with three standard window designs: (1) a clear double pane window, (2) a standard low-e window (Row \#3 of Table S2), and (3) a high performance low-e window (Row \#4 of Table S2). The construction of each window used the same $6 \mathrm{~mm}$-thick clear glass for the outer pane (see glazing \#3 of Table S4), a 13mm-thick Argon gas spacer layer, and one of the glazings from Table S4 for the inside window pane. The values for our smart glazing were extracted from experimentally measured optical spectra ranging from $300 \mathrm{~nm}-25 \mu \mathrm{m}$ (shown in Fig. $\mathbf{2}$ and $\mathbf{3}$ of the main text). Optical parameters of the static window glazings (\#3 to \#5) were extracted from the default values found in the EnergyPlus library. Details on the construction materials are shown in Table S5.

\begin{tabular}{|c|c|c|c|c|c|}
\hline $\begin{array}{c}\text { Parameter Name } \\
\text { (All values are spectral averages at } \\
\text { normal incidence) }\end{array}$ & $\begin{array}{l}\text { PCM } \\
(\mathbf{A m})\end{array}$ & $\begin{array}{l}\text { PCM } \\
\text { (Cry) }\end{array}$ & $\begin{array}{l}\text { Clear } \\
\text { Glass }\end{array}$ & $\begin{array}{l}\text { Low-E } \\
\text { Glass } \\
\text { (Std.) }\end{array}$ & $\begin{array}{c}\text { Low-E } \\
\text { Glass } \\
\text { (High } \\
\text { Perf.) }\end{array}$ \\
\hline Glazing number & $\# 1$ & $\# 2$ & \#3 & $\# 4$ & \#5 \\
\hline Thickness (mm) & 6 & 6 & 6 & 6 & 6 \\
\hline Total Solar Transmittance & 0.215 & 0.171 & 0.775 & 0.6 & 0.43 \\
\hline Outward Solar Reflectance & 0.527 & 0.389 & 0.071 & 0.22 & 0.45 \\
\hline Inward Solar Reflectance & 0.576 & 0.579 & 0.071 & 0.17 & 0.3 \\
\hline Visible Transmittance & 0.524 & 0.408 & 0.881 & 0.84 & 0.69 \\
\hline Outward Visible Reflectance & 0.043 & 0.033 & 0.08 & 0.078 & 0.06 \\
\hline Inward Visible Reflectance & 0.149 & 0.165 & 0.08 & 0.055 & 0.07 \\
\hline Infrared Transmittance & 0 & 0 & 0 & 0 & 0 \\
\hline Outward Infrared Emissivity & 0.137 & 0.112 & 0.84 & 0.1 & 0.03 \\
\hline Inward Infrared Emissivity & 0.84 & 0.84 & 0.84 & 0.84 & 0.84 \\
\hline Thermal Conductivity $(\mathrm{W} / \mathrm{m} \cdot \mathrm{K})$ & 0.9 & 0.9 & 0.9 & 0.9 & 0.9 \\
\hline
\end{tabular}

Table S4: Optical and thermal properties of window glazings used in energy savings simulations. 


\begin{tabular}{|c|c|c|c|c|c|c|}
\hline $\begin{array}{c}\text { Construction } \\
\text { Material (from } \\
\text { outside to inside) }\end{array}$ & $\begin{array}{c}\text { Cond. } \\
(\mathrm{W} / \mathrm{m}-\mathrm{K})\end{array}$ & $\begin{array}{l}\text { Thickness } \\
\text { (m) }\end{array}$ & $\begin{array}{c}U \\
(W / m-K)\end{array}$ & $\begin{array}{c}\mathbf{R} \\
(\mathrm{m}-\mathrm{K} / \mathrm{W})\end{array}$ & $\begin{array}{l}\text { Density } \\
(\mathrm{kg} / \mathrm{m})\end{array}$ & $\begin{array}{c}\mathrm{C} \\
(\mathrm{J} / \mathrm{kg}-\mathrm{K})\end{array}$ \\
\hline \multicolumn{7}{|l|}{ WALLS } \\
\hline Wood siding & 0.14 & 0.009 & 15.556 & 0.064 & 530 & 900 \\
\hline Fiberglass quilt & 0.04 & 0.066 & 0.606 & 1.65 & 12 & 840 \\
\hline Plaster board & 0.16 & 0.012 & 13.333 & 0.075 & 950 & 840 \\
\hline \multicolumn{7}{|l|}{ ROOF } \\
\hline Roof deck & 0.14 & 0.019 & 7.368 & 0.136 & 530 & 900 \\
\hline Fiberglass quilt & 0.04 & 0.066 & 0.606 & 1.65 & 12 & 840 \\
\hline Plaster board & 0.16 & 0.01 & 1.6 & 0.625 & 950 & 840 \\
\hline \multicolumn{7}{|l|}{ FLOOR } \\
\hline C5 Concrete & 1.73 & 0.1015 & 17.04 & 0.059 & 2243 & 837 \\
\hline
\end{tabular}

Table S5: Physical properties construction materials and layers of walls, roof, and floor used in energy savings simulations (values extracted from EnergyPlus documentation).

In order to direct compare our smart window with the three static window designs, all simulation parameters were held constant for a given location, with only the inside window pane varied according to the values in Table S4. For all days simulated, we used a constant $20 \mathrm{C}$ and $24 \mathrm{C}$ for the heating and cooling setpoints, respectively, and ran our simulations for an entire year from January 1 to December 31 using publicly available weather data available from EnergyPlus' database (https://energyplus.net/weather). The dimensions and orientation of our simulated office building can be seen in Fig. S9a.

Fig. S9b compares the relative annual energy savings of using our smart window compared to the three static window designs we mentioned above. We used a simple algorithm (i.e. always minimize heating/cooling energy regardless of number of switching events) to determine when to switch the smart window between its amorphous and crystalline states. Note: In all the results shown in Fig. S9, we account for each amorphization/crystallization switching event across a total smart window area of $12 \mathrm{~m}^{2}$ by using the measured switching energy per unit area shown in Fig. 4c of the main text. Our design has a clear advantage over using an uncoated double pane window (blue bars) with total energy savings ranging from $20 \%$ to $34 \%$ annually. We attribute this to both energy harvesting and the low-e coating of our smart window (outward emissivity ranging from 0.112 in the crystalline state to 0.137 in the amorphous state) which both aids with heating during cool months and preventing unwanted thermal transmission in both the winter and summer. We can quantify the efficiency gains due to energy harvesting by comparing our energy savings with a standard low-e double pane window (red bars in Fig. S9b). As the emissivity of the outer low-e surface is similar to our smart glazing (emissivity of 0.1 ), the simulated energy savings can be attributed primarily to solar energy harvesting during the colder months. 
a

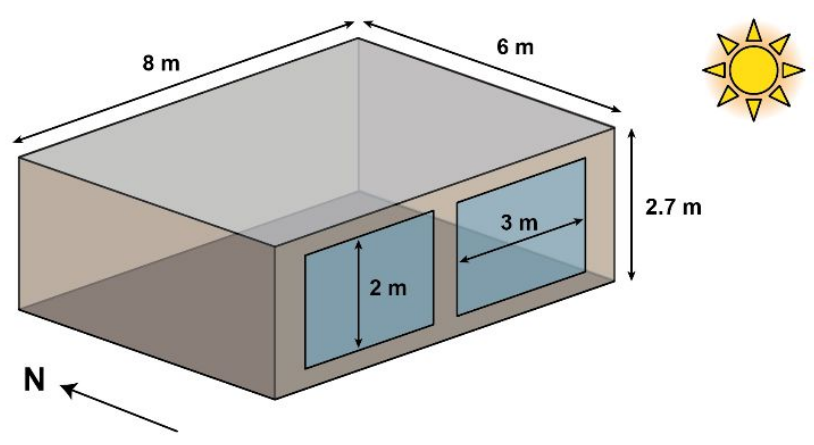

b

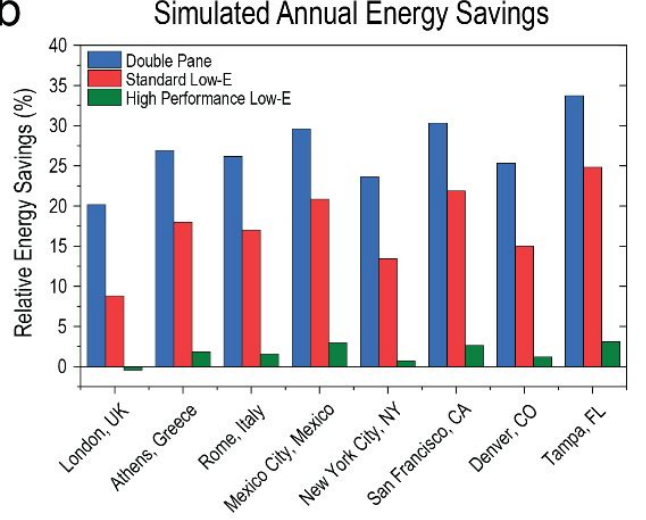

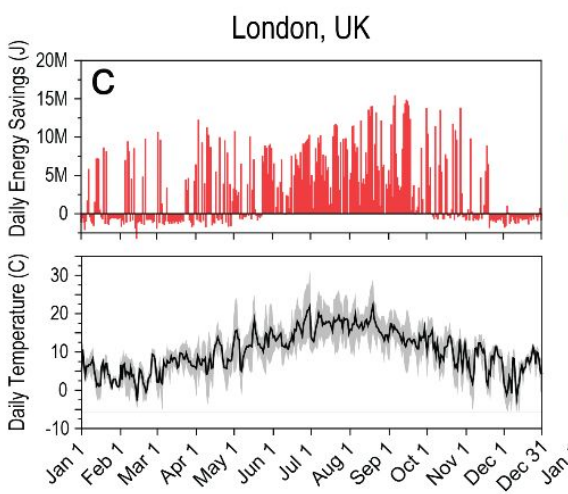

San Francisco, CA

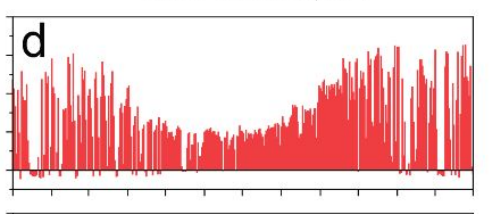

Tampa, FL

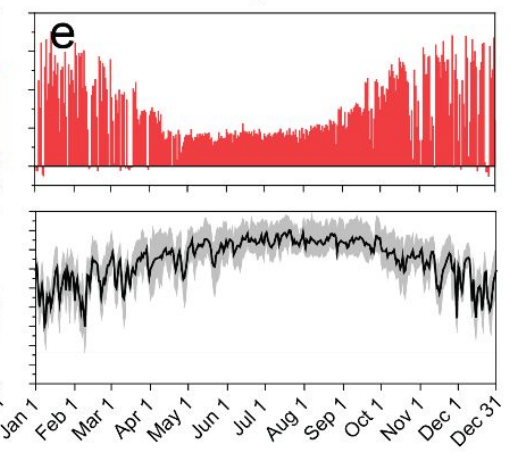

Fig. S9: Energy savings comparison with three static window designs. (a) Schematic of office building used in the simulations. Two $2 \times 3 \mathrm{~m}^{2}$ double-paned windows were installed in the south-facing wall of the building. (b) Comparison of relative energy savings using our phase-change smart window versus static windows with no low-e coating (blue), a standard low-e coating (red), and a high performance low-e coating (green). (c)-(e) Simulated daily energy savings (in Joules) and temperatures (average daily temperature in black, minimum and maximum daily temperature swing in grey) from three of the locations plotted in (b).

We can directly observe this energy harvesting by plotting the daily energy savings and temperatures in Fig. S9c-e over the entire year. For cities with lower cloud coverage (San Francisco and Tampa have approximately twice the number of sunny hours per year on average than London), the daily energy savings are largest in the cooler months and smallest than in the warmer months. Interestingly, the energy savings during the warmer months (temperatures greater than the heating setpoint of 20C) can be attributed to both high reflection of near-IR solar radiation during the day and higher emissivity during the night when the window is in the amorphous state (hourly runs used to calculate the results in Fig. S9 not shown here). This is an additional advantage to our design which favourably modulates both the near-IR and far-IR spectral properties of the window.

When comparing our window against a double pane window with a high performance low-e coating (emissivity of 0.03 ), we still observe modest energy savings (between $0.7 \%$ and $3.1 \%$ ) for most locations other than London (attributed to cloud coverage as mentioned above). The main reason for the reduces energy savings is due to the better thermal properties of a highly optimized low-e window compared with our initial demonstration which serves to reduce unwanted thermal energy transfer (esp. heat loss at night during the winter months). However, despite a $\sim 37 \times$ reduction in emissivity compared to our smart window in the crystalline state, the fact that we observe an overall gain in energy efficiency in 7 out of 8 locations is quite impressive. We attribute this partly to our amorphous window's ability to 
more efficiently radiate thermal energy away from the building at night during the summer in addition to the energy harvesting we have highlighted in the main text. To further improve our smart window's performance, more optimization is needed which includes the entire visible, near-IR, and far-IR spectrum of our glazing in both states. 


\section{Supplementary Note 8}

\section{Cycling failure in larger devices}

In Fig. S10, we show the cycling data for a device with $4 \times$ greater pixel area than Fig. 4 of the main text. In this device, higher energy pulses were needed to switch the larger device. Degradation in the reflected optical contrast and microscope images indicate two possible causes of failure: 1) phase segregation in the PCM due to higher device temperatures and thermal gradients; or 2) degradation of the thin Ag layers due to higher temperature cycling. Further analysis is needed to precisely determine the root cause of failure in larger devices.
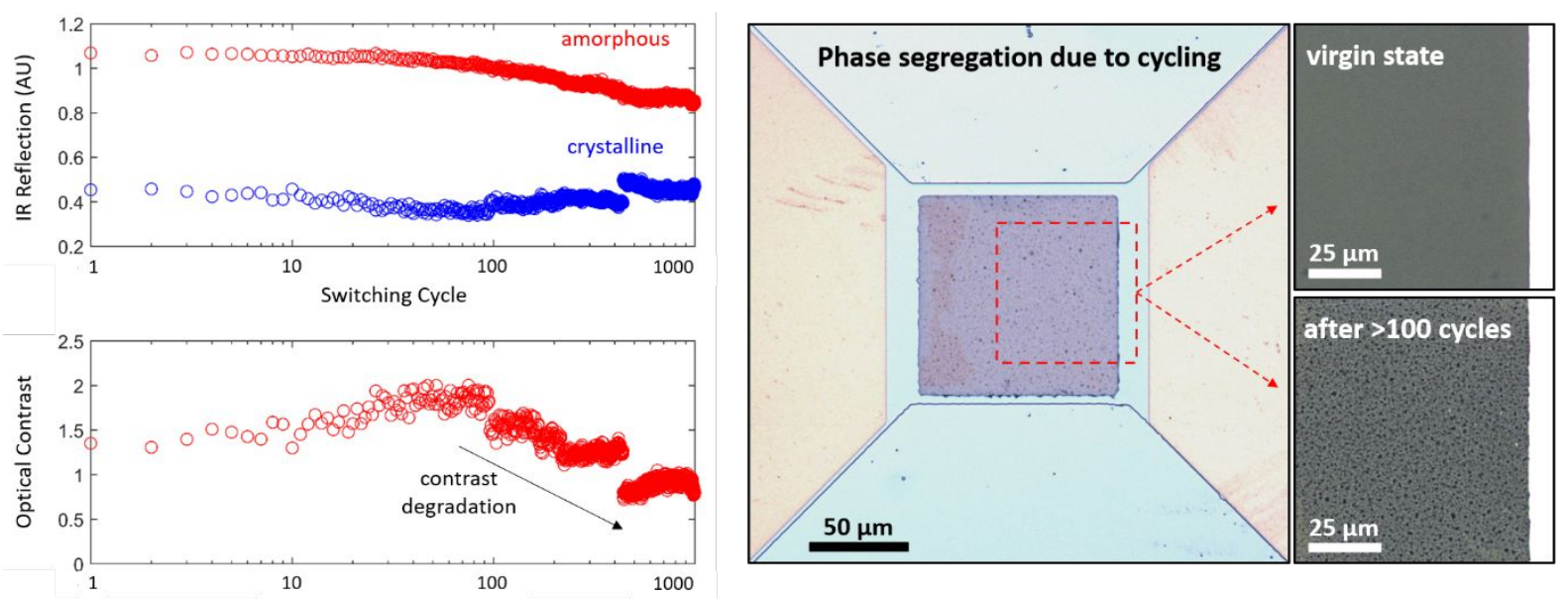

Fig. S10: Cycling in larger device $(100 \mu \mathrm{m} \times 100 \mu \mathrm{m}$ pixel $)$ shows degradation in optical contrast after 100 cycles. Optical transmission microscope images (right) show inhomogeneities indicating phase segregation or degradation of the Ag layer as the possible cause of failure. 


\section{Supplementary Note 9}

\section{Addressing scalability}

Here, we present a low-cost strategy for addressing a large array of phase-change pixels across a window that is $1 \times 1 \mathrm{~m}^{2}$ in size. It is worth noting that since the pixels are nonvolatile and can be switched sequentially, there is no need to use a complex active backplane to control the pixels and a simple resistive network with passive nonlinear selectors (i.e. diodes or OTS thin-films ${ }^{17,18}$ such as $\mathrm{Ge}_{30} \mathrm{Se}_{70}$ ) is sufficient. This significantly reduces the cost of manufacturing compared to display technologies. Fig. S11 shows the proposed layout used to switch 4 pixels simultaneously. The bottom electrode is in contact with one side of the FTO microheater, while the top electrode is in contact with the other through an OTS selector. The top electrode is electrically isolated from the bottom electrode by a thin dielectric layer (e.g. PECVD $\mathrm{SiO}_{2}$ ). Addressing multiple pixels simultaneously in this manner helps to simplify the control circuitry needed to switch the entire window.

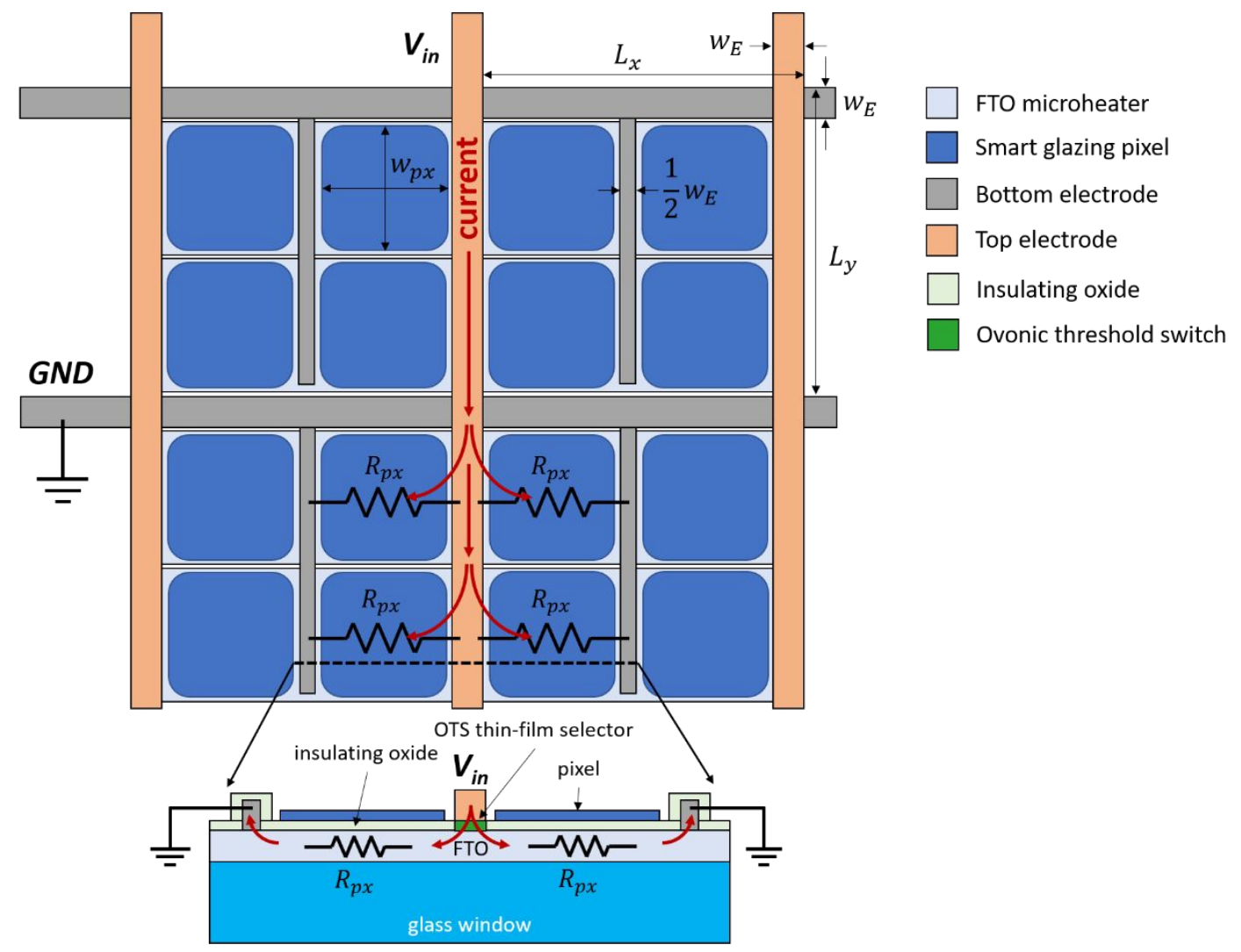

Fig. S11: Schematic of metal electrode network used to switch four pixels simultaneously.

\section{Estimating Ohmic Losses:}

To minimize shadowing from the metal electrodes, we wish to minimize the contact width ( $\left.w_{E}\right)$ relative to the pixel dimensions $\left(w_{p x}\right)$. However, the material used for the electrodes will have a maxim current density which will limit the minimum dimensions of the electrodes. If we use aluminium alloy electrodes (e.g. $\left.\mathrm{Al}_{0.96} \mathrm{Cu}_{0.04}\right)$ to minimize cost while maximizing durability ${ }^{19}$, the maximum DC current density for this material is approximately $J_{\max } \sim 4 \times$ $10^{6} \mathrm{~A} / \mathrm{cm}^{2}$ at an elevated temperature of $125 \mathrm{C}$. We note that in our case, the maximum current density should be greater than this since we are using very short pulses to switch the smart glazing pixels ( $\tau_{c r y}=45 \mu \mathrm{s}$ and $\tau_{a m}=100 \mu$ s for pixels that are $100 \times 100 \mu \mathrm{m}^{2}$ in size). Additionally, changing the directionality of the current between pulses has been demonstrated 
to self-heal voids and reduce electromigration in on-chip metal interconnects ${ }^{20}$ and could be used to further improve the lifetime of the electrodes. Using a more conservative $J_{\max } \sim 10^{5}$ $\mathrm{A} / \mathrm{cm}^{2}$ and an experimentally obtained peak power of $P_{a m}=1.57 \mathrm{~W}\left(E_{a m}=74 \mu \mathrm{J}\right)$ required to amorphize a $100 \times 100 \mu \mathrm{m}^{2}$ pixel, the minimum electrode area can be estimated as:

$$
A_{E}=w_{E}^{2}=\frac{4}{J_{\max }} \sqrt{\frac{P_{a m}}{R_{p x}}}
$$

where we have assumed an electrode with a square cross section and have multiplied by $4 \times$ to account for the current required to switch four pixels in parallel as shown in Fig. S11. Using the measured value $R_{p x}=21 \Omega$ for our pixel and a resistivity of $\rho_{A l_{0.96}} \mathrm{Cu}_{0.04}=2.7 \mu \Omega$-cm for the electrodes ${ }^{19}$, the corresponding minimum electrode width is $w_{E}=11 \mu \mathrm{m}$. In reality, it is advantageous to use a larger electrode cross section to reduce Ohmic losses across a large window since $R \propto l$. In Fig. S12 we plot the percentage of power lost due to the metal electrodes relative to the pixels being switched with $w_{E}=25 \mu \mathrm{m}$ for electrodes with a square cross section.
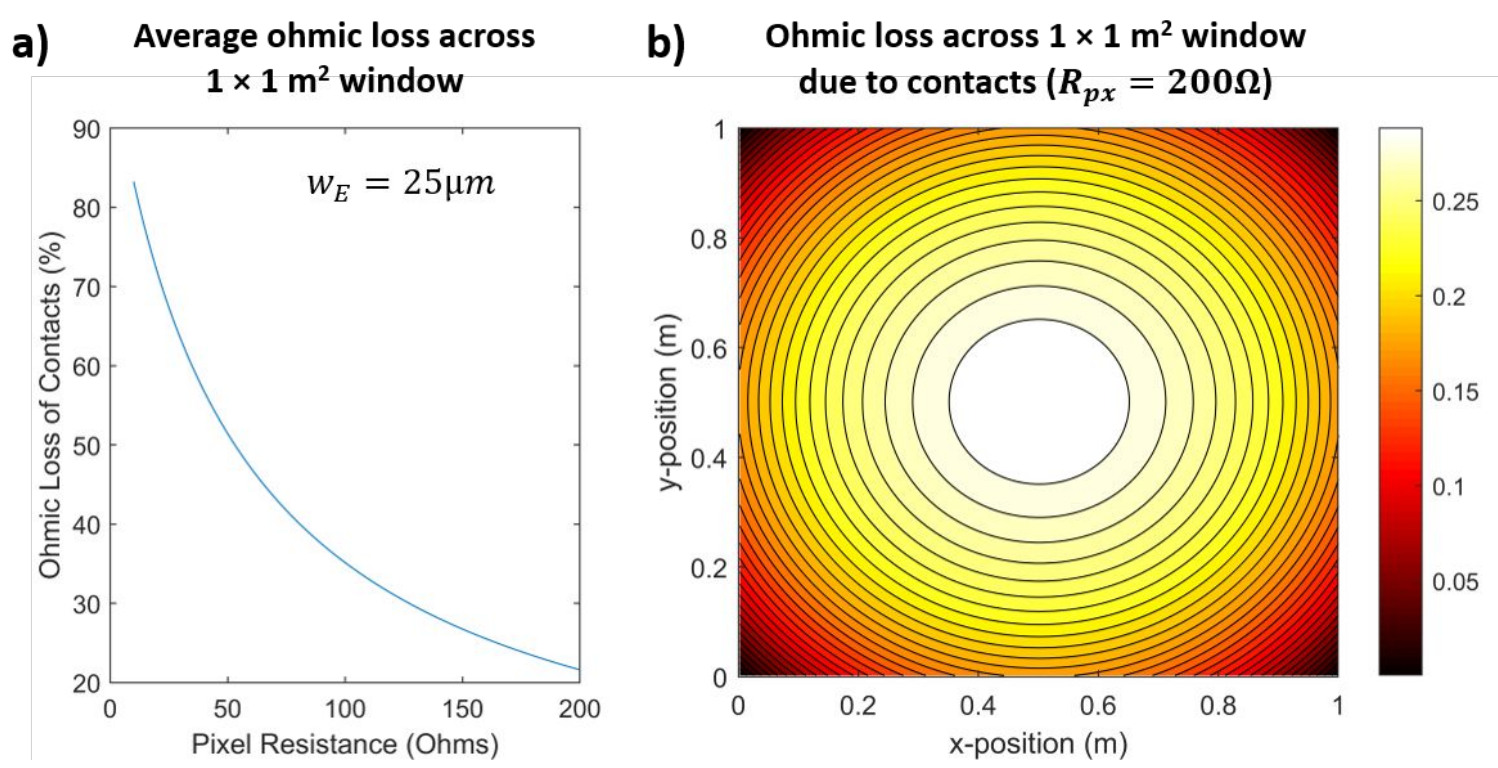

Fig. S12: a) Average ohmic loss versus pixel resistance across a one square meter window with edge contacts. b) Distribution of ohmic loss across window for a pixel resistance of $R_{p x}$ $=200 \Omega$. The center of the window experiences the largest loss due to the longest path length.

We see from Fig. S12 that increasing $R_{p x}$ reduces the ohmic loss (or parasitic resistance) of our design. The trade-off of increasing $R_{p x}$ is a higher switching voltage $\left(V_{a m} \propto \sqrt{R_{p x}}\right)$ which will place a lower limit on the thickness of the dielectric insulating layer in order to prevent dielectric breakdown. This is a worthwhile trade-off since increasing the voltage also serves to reduce the current needed to switch the pixels which reduces the effects of electromigration in the metal electrodes. Using an FTO layer with a higher sheet resistance (e.g. reducing the FTO thickness) is a straightforward method to increase $R_{p x}$. 


\section{Shadowing Effects and Pixel Count:}

Increasing the metal electrode cross-sectional area (i.e. increasing $w_{E}$ ) also can reduce ohmic loss by decreasing the resistance of the electrodes. However, increasing the width of the electrodes relative to the pixel dimensions will increase the fraction of the window shadowed by the contacts. For example, in the case of $w_{p x}=100 \mu \mathrm{m}$ and $w_{E}=25 \mu \mathrm{m}$, approximately $30 \%$ of the window will be shadowed by the electrodes and will reduce the overall transmission. Increasing the pixel dimensions will significantly help to overcome this issue (e.g. increasing $w_{p x}$ to $500 \mu \mathrm{m}$, reduces the shadowing effect to less than $8 \%$ ) while also reducing the number of addressable regions of the window. Fig. S13a plots the total number of addressable pixel regions (each region has four pixels) as a function of pixel width $\left(w_{p x}\right)$ for a $1 \times 1 \mathrm{~m}^{2}$ window. The number of regions requiring switching drops significantly as the pixel width increases (approximately $10^{6}$ for $w_{p x}=500 \mu \mathrm{m}$ ). While increasing the pixel dimensions does not impact the pixel resistance, the peak power required to reversibly switch the pixel $\left(P_{a m}\right)$ does increase. Empirically, we find that $P_{a m} \propto w_{p x}^{1.21 \pm 0.08}$ (see Fig. 4c of main text). We anticipate that for larger pixels which are less dominated by edge effects (i.e. heating an unnecessarily large volume of material in contact with the pixel perimeter), the switching energy will scale linearly with the pixel's area. Fig. S13b shows the estimated fraction of window covered by contacts as a function of pixel width for a fixed resistance and fixed current density through the metal electrodes. Again, increasing the pixel dimensions by a factor of 5 10× significantly improves the performance of the smart window. While we have shown reversible switching for pixel dimensions up to $w_{p x}^{2}=100 \times 100 \mu \mathrm{m}^{2}$, further work is needed to increase $w_{p x}$ while addressing failure mechanisms in larger pixel designs (see Supplementary Note 9).
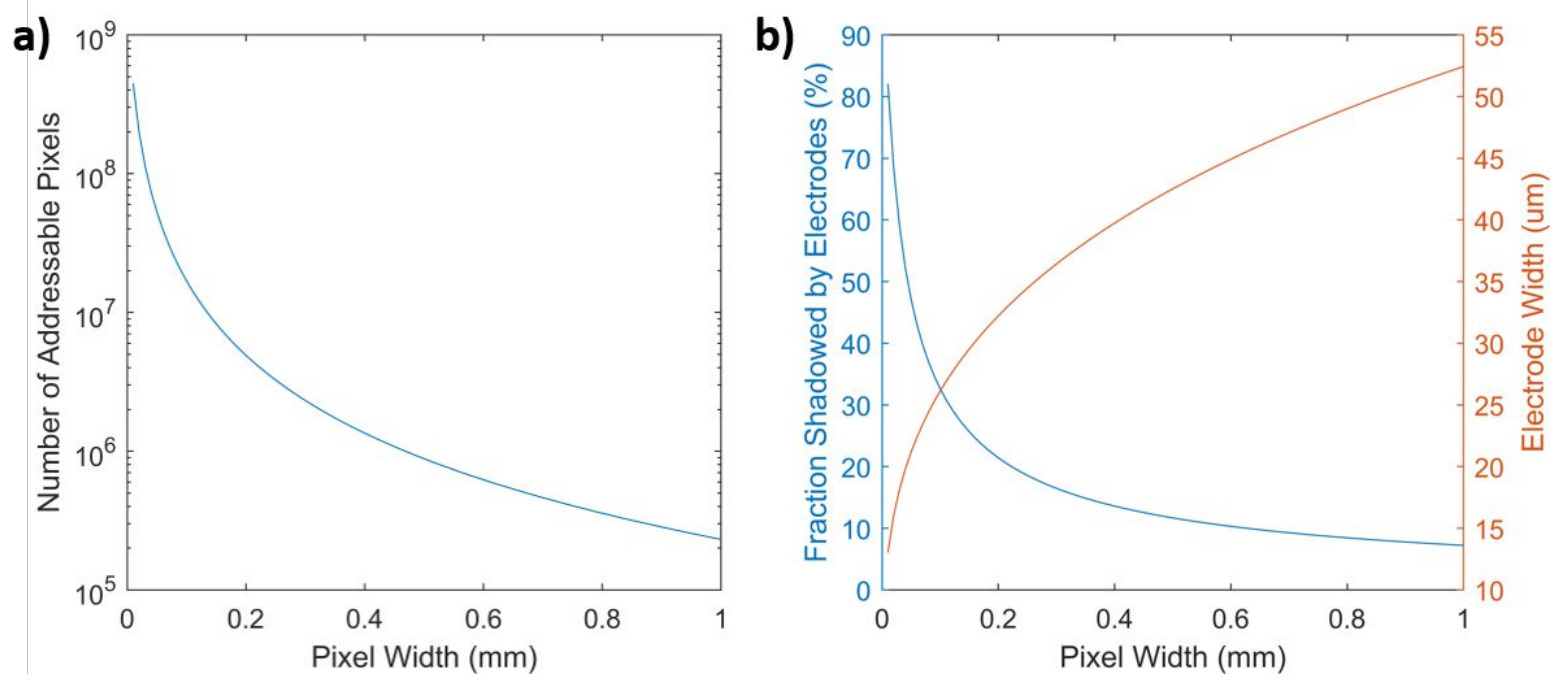

Fig. S13: a) Total number of pixel regions (assuming four pixels per region) as a function of pixel width $\left(w_{p x}\right)$ for a one square meter window with edge contacts. b) Estimated fraction of window shadowed by metal electrodes versus pixel width. The dimensions of the electrode were increased to maintain constant current density with increasing $P_{a m}$. 


\section{Supplementary References:}

1. Pettersson, L. A. A., Roman, L. S. \& Inganäs, O. Modeling photocurrent action spectra of photovoltaic devices based on organic thin films. J. Appl. Phys. 86, 487-496 (1999).

2. Lawrence Berkeley National Laboratory. WINDOW: A computer program for calculating total window thermal performance indices.

https://windows.lbl.gov/software/window.

3. World's most adopted Dynamic Glass | Suntuitive Dynamic Glass. https://suntuitiveglass.com/.

4. Halio: Smart-tinting glass system. http://halioglass.eu/.

5. iplus top 1.1t on Clearlite AGC Yourglass. https://www.agcyourglass.com/tr/en/products/iplus/iplus-top-11t-on-clearlite.

6. ipasol | AGC Yourglass. https://www.agc-yourglass.com/gb/en/brands/ipasol.

7. Zhang, Z. et al. Solution-based fabrication of vanadium dioxide on F:SnO2 substrates with largely enhanced thermochromism and low-emissivity for energy-saving applications. Energy Environ. Sci. 4, 4290 (2011).

8. Chen, Z. et al. Fine crystalline VO2 nanoparticles: synthesis, abnormal phase transition temperatures and excellent optical properties of a derived VO2 nanocomposite foil. J. Mater. Chem. A 2, 2718 (2014).

9. Ke, Y. et al. Controllable Fabrication of Two-Dimensional Patterned VO 2 Nanoparticle, Nanodome, and Nanonet Arrays with Tunable Temperature-Dependent Localized Surface Plasmon Resonance. ACS Nano 11, 7542-7551 (2017).

10. Li, X.-H., Liu, C., Feng, S.-P. \& Fang, N. X. Broadband Light Management with Thermochromic Hydrogel Microparticles for Smart Windows. Joule 3, 290-302 (2019).

11. Llordés, A., Garcia, G., Gazquez, J. \& Milliron, D. J. Tunable near-infrared and visible-light transmittance in nanocrystal-in-glass composites. Nature 500, 323-326 (2013).

12. Kraft, A. \& Rottmann, M. Properties, performance and current status of the laminated electrochromic glass of Gesimat. Sol. Energy Mater. Sol. Cells 93, 2088-2092 (2009).

13. Garcia, G. et al. Near-Infrared Spectrally Selective Plasmonic Electrochromic Thin Films. Adv. Opt. Mater. 1, 215-220 (2013).

14. Barile, C. J. et al. Dynamic Windows with Neutral Color, High Contrast, and Excellent Durability Using Reversible Metal Electrodeposition. Joule 1, 133-145 (2017).

15. Ghosh, A., Norton, B. \& Duffy, A. Measured overall heat transfer coefficient of a suspended particle device switchable glazing. Appl. Energy 159, 362-369 (2015).

16. Du, K.-K. et al. Control over emissivity of zero-static-power thermal emitters based on phase-changing material GST. Light Sci. Appl. 6, e16194-e16194 (2017).

17. Noé, P. et al. Toward ultimate nonvolatile resistive memories: The mechanism behind ovonic threshold switching revealed. Sci. Adv. 6, eaay2830 (2020).

18. Verdy, A. et al. Improved Electrical Performance Thanks to Sb and N Doping in Se- 
Rich GeSe-Based OTS Selector Devices. in 2017 IEEE International Memory Workshop (IMW) 1-4 (IEEE, 2017). doi:10.1109/IMW.2017.7939088.

19. Ames, I., D’Heurle, F. M. \& Horstmann, R. E. Reduction of Electromigration in Aluminum Films by Copper Doping. IBM J. Res. Dev. 14, 461-463 (1970).

20. Maiz, J. A. Characterization of electromigration under bidirectional (BC) and pulsed unidirectional (PDC) currents. in 27th Annual Proceedings., International Reliability Physics Symposium 220-228 (IEEE). doi:10.1109/RELPHY.1989.36349. 